\title{
A HOSPITALIDADE E OS MIGRANTES NORDESTINOS NO BIXIGA (SÃO PAULO/SP)
}

\begin{abstract}
Anna Paula Telino de Abreu Fernandes ${ }^{1}$
Sênia Regina Bastos ${ }^{2}$

\section{Resumo:}

Objetiva-se neste trabalho compreender as relações de hospitalidade estabelecidas entre os migrantes nordestinos e a sociedade de acolhimento no Bixiga. Realizou-se um estudo exploratório, por meio da observação participante e entrevistas abertas semiestruturadas, gravadas e transcritas. Constatou-se que o acolhimento do migrante nordestino não é incondicional; conflitos, imposição de regras de conduta e de condições por parte da sociedade de acolhimento foram observados, bem como hostilidade e comportamentos xenofóbicos em relação a eles em algumas situações. Apesar da contribuição dessa comunidade para o desenvolvimento do território, é perceptível o seu apagamento e falta de representatividade, por serem encarados como indivíduos inferiorizados, indignos de reconhecimento, enquanto os italianos são vistos como os responsáveis por tornar o Bixiga referência nacional.
\end{abstract}

Palavras-chave: Migrantes nordestinos. Bixiga. Acolhimento. Pertencimento. Hostilidade.

\section{HOSPITALITY AND THE NORTHEASTERN MIGRANTS IN BIXIGA (SÃO PAULO/SP)}

\begin{abstract}
:
The aim of this paper is to understand the hospitality relations established between Northeastern migrants and the host society in Bixiga. An exploratory study was carried out, through participant observation and semi-structured open interviews, recorded and transcribed. It was found that the northeastern migrant's welcoming is not unconditional; conflicts, imposition of rules of conduct and conditions by the host society were observed, as well as hostility and xenophobic behavior towards them in some situations. Despite the contribution of this community to the development of the territory, their erasure and lack of representativeness are noticeable, as they are seen as inferior individuals, unworthy of recognition, while Italians are seen as responsible for making Bixiga a national reference.
\end{abstract}

Keywords: Northeastern migrants. Bixiga. Welcoming. Belonging. Hostility.

\footnotetext{
${ }^{1}$ Mestre em Hospitalidade pela Universidade Anhembi Morumbi, Brasil (2020), estágio em docência na Universidade Anhembi Morumbi, São Paulo.

${ }^{2}$ Professora da Universidade Anhembi Morumbi. Doutora em História pela Pontifícia Universidade Católica de São Paulo.
} 


\section{Introdução}

Dentre os fenômenos sociais existentes, as migrações se enquadram em diversas linhas de pesquisa, por não se limitarem apenas ao aspecto do movimento populacional em si. Os deslocamentos populacionais ocorrem dentro do próprio país - migrações internas - ou de um país para o outro - migrações internacionais - e acontecem por diversos motivos. Dentre as razões, as econômicas são determinantes; estas se relacionam à falta de condições dignas de sobrevivência e os sujeitos fogem da pobreza, da fome, dentre outras circunstâncias, em busca de melhoria de vida e de trabalho (CHUEIRI; CÂMARA, 2014).

Nesse contexto, São Paulo/SP há anos é considerada uma cidade capaz de prover melhores oportunidades e atrai migrantes das mais diversas partes do Brasil e do mundo (CHUEIRI; CÂMARA, 2014). A partir do século XIX, o Bixiga recebeu grande contingente de imigrantes italianos e eles se tornaram seu símbolo de representação. Contudo, nos seus primórdios, foi ocupado por ex-escravos, tendo sido um importante quilombo da cidade - o Saracura (CASTRO, 2008; BITELLI, 2017; LUCENA, 2013), mas cuja memória é ocultada nas narrativas de divulgação de território italiano.

Dos migrantes nacionais que chegaram a São Paulo, os nordestinos se destacam não apenas por seu número expressivo, mas também pela contribuição para o seu desenvolvimento. $\mathrm{O}$ aumento das migrações nordestinas para a cidade foi observado inicialmente em 1915 e as motivações para tal foram diversas, desde fatores econômicos até condicionantes ambientais, como as secas dos sertões (OLIVEIRA; JANNUZZI, 2005; OJIMA; COSTA; CALIXTA, 2014; PAIVA, 2004). A partir da década de 1950, o Bixiga tornou-se destino atraente para os migrantes nordestinos, devido a sua proximidade ao centro da cidade e à presença de habitações populares de baixo custo de aluguel - os cortiços (LUCENA, 2013). Considerado um território de migração, multiétnico, rico em diversidade, atualmente é ocupado, sobretudo, pelos negros, nordestinos, mineiros e descendentes de italianos (CASTRO, 2008), onde o contato com a alteridade é constante.

Um território de migração é um espaço urbano que foi alterado por grupos de migrantes - nacionais e/ou internacionais - como reflexo da dinâmica dos deslocamentos populacionais, o que, portanto, o torna híbrido; em suma, é um espaço cujo desenvolvimento social, econômico e cultural é considerado complexo e não é idílico (PAIVA, 2011). O Bixiga, dessa forma, é privilegiado para a investigação de questões referentes à hospitalidade, uma vez que, ao longo dos anos, foi capaz de se constituir como um local no qual, supostamente, há espaço para todos, mas, ao mesmo tempo, mantem divisões fundamentadas nas desigualdades. Sobretudo porque, apesar dessa característica híbrida, é possível ainda identificar a afirmação da "italianidade" do território enquanto se tenta apagar ou ofuscar aqueles que não são italianos, alertanto para uma convivência não isenta de conflitos entre as comunidades ali presentes (CASTRO, 2008).

Nesse sentido, este trabalho tem por objetivo compreender as relações de hospitalidade que são estabelecidas entre os migrantes nordestinos e a sociedade de 
acolhimento no Bixiga. Visa, ainda, contribuir para o estudo do trato com o migrante, que precisa ser acolhido e integrado à sociedade que o recebe; nesse sentido, buscou-se analisar as dimensões da hospitalidade que são evidenciadas nesse fenômeno. Além disso, reflete sobre o Bixiga italiano, como é reconhecido até os dias atuais. Por fim, traz contribuições à literatura, pelo fato de ser um estudo contemporâneo sobre migração nordestina, tema de baixa incidência acadêmica, apesar de sua alta pertinência.

Para tanto, foi conduzida uma pesquisa exploratória, por meio da realização de observação participante e entrevistas abertas semiestruturadas gravadas, transcritas na íntegra e, posteriormente, submetidas à análise de conteúdo (CRESWELL, 2010; BARDIN, 1977). O corpus da pesquisa foi composto por relatos de onze sujeitos, dentre os quais sete são migrantes nordestinos e quatro são paulistanos; as origens distintas das pessoas entrevistadas foram importantes, sobretudo, para investigar percepções diferentes sobre as relações interpessoais estabelecidas no Bixiga, que formam a base da hospitalidade (CAMARGO, 2015; SANTOS; PERAZZOLO, 2012).

\section{A hospitalidade e o migrante}

A palavra Hospitalis é derivada de hospes, cujo significado é "aquele que recebe o outro" e dará origem à palavra hospitalitas, "o gesto de acolhida e de hospedagem gratuita" (GRASSI, 2011). Hostis, por sua vez, significa "aquele que é acolhido" e, em contrapartida, também pode significar "inimigo". Ainda dentro dessa família de palavras, encontra-se o verbo hostire, que se refere a "igualar". Dessa forma, a palavra hospitalidade remete a um gesto de proteção, de compensação e de igualização em um mundo onde o estrangeiro não tem lugar, sendo, por muitos, encarado como inimigo (BENVENISTE, 1995; GRASSI, 2011).

Com base na etimologia do termo, não existe hospitalidade sem a relação entre hospedeiro - aquele que recebe - e hóspede - aquele que é recebido. Para que essa relação exista, entretanto, é necessária a entrada do hóspede em um espaço e a existência de um ritual de acolhida por parte do hospedeiro. O espaço referido pode ser geográfico ou psíquico e o gesto de hospitalidade, geralmente, não é espontâneo nem confortável (GRASSI, 2011).

Derrida ([1997] 2001) definiu que a hospitalidade representa cultura e considera que a ética é a própria experiência da hospitalidade. O autor defende, ainda, que a lei da hospitalidade é incondicional e ilimitada (DERRIDA, 2003). Para Kant ([1795] 1989), a hospitalidade não representa filantropia e, sim, o direito de um estrangeiro não ser tratado como um inimigo, ao adentrar em um território alheio. Entretanto, este não pode pretender residir no local, apenas visitá-lo, ou seja, o autor defende uma hospitalidade regida por regras e imposições. Portanto, a hospitalidade incondicional defendida por Derrida ([1997] 2001) compreende a exposição ao risco, uma abertura ao desconhecido (PEREIRA, 2017).

Raffestin (1997), no entanto, afirma que a hospitalidade representa um rito de passagem, uma dádiva temporária, fator corroborado por Montadon (2011) ao acrescentar o caráter provisório da permanência e a necessidade de manter o estrangeiro 
como tal - reforçando o que fora dito por Kant ([1795] 1989) -, preservando-o à distância, a fim de manter sua identidade, sua originalidade, sua singularidade.

A partir do exposto, é possível observar que, nos fundamentos da hospitalidade, a presença do estrangeiro é um tema recorrente. Ao contrário do que se possa imediatamente pensar, o estrangeiro não é apenas representado por indivíduos advindos de outros países, mas configura qualquer sujeito que apresente comportamento atípico, que seja de outra etnia, que fale outro idioma ou porte um sotaque diferente, que apresente ideias ou visões de mundo incomuns a um determinado grupo de sujeitos (BOFF, 2005), ou seja, todo aquele que é considerado "estranho", é um estrangeiro (PEREIRA, 2017). Partindo desse pressuposto, todo migrante, ao chegar à sociedade de acolhimento, converte-se em um estrangeiro.

Nesse sentido, o migrante, ao chegar nessa sociedade, pode ser encarado de diversas maneiras: “[...] a diferença (a compreender), a anomalia (a corrigir), o perigo (a eliminar), o recém-chegado (a iniciar), o inimigo (a combater), o viajante (a proteger), o convidado (a acolher), mais globalmente o tabu (a evitar ou controlar), [...] o estranho (a familiarizar)" (BOUDOU, 2017, p. 101). Por diversas vezes, é estereotipado e a ele é conferida uma identidade negativa; além disso, é interessante, ainda, constatar que com frequência é incluído na desordem urbana da cidade (GRASSI, 2011).

Acredita-se que, para que o migrante possa ser aceito em uma sociedade, ele necessita passar por um rito de passagem, composto por diversos ritos que organizam uma mudança de estado (BOUDOU, 2017). Nesse sentido, o acolhimento e a solidariedade são dimensões da hospitalidade que emergem da relação entre o hospedeiro e o hóspede com base no reconhecimento da sua individualidade, estabelecendo uma relação de alteridade (STEFANELLI; BASTOS, 2016). A hospitalidade, portanto, acima de tudo, visa ao respeito à alteridade, ficando no limite entre a rejeição e a absorção (MONTADON, 2011).

\section{Migrações nordestinas para São Paulo}

Durante anos foi pouco expressivo o deslocamento dos nordestinos para São Paulo e isso se deu por algumas razões. Primeiramente, pela carência de meios de transporte que permitissem um fluxo significativo de nordestinos para o Sudeste; segundo pois, na Amazônia, a extração do látex estava em seu auge e era executada majoritariamente por nordestinos; por último, por ter sido construída a ideologia de que o nordestino era apático, pouco dedicado ao trabalho agrícola e sem qualificação para trabalhar em fábricas, em oposição aos europeus, que eram tidos como competentes em qualquer trabalho executado e eram adequados à cidade, uma vez que ela buscava se desenvolver conforme os moldes de comportamento europeu (VILLA, 2017).

Ainda nesse contexto de discussão, as causas que propiciaram a migração em massa dos nordestinos para outras regiões brasileiras, especialmente para São Paulo são vastamente discutidas, contudo, é sabido que

Os motivos que impulsionaram o migrante a sair da terra de antes em busca de novas formas de viver são decorrentes de inúmeros fatores, os adversos de expulsão e outros de atração, tais como: questões 
econômicas - miséria, fome, desemprego, latifúndio, exploração nas relações de trabalho, de terra para a economia de subsistência, estratégia camponesa para preservação do sítio, implantação da atividade pecuária; questões ambientais - variações climáticas (enchentes e secas), esgotamento dos solos; questões psicossociais - conflitos locais, frustrações, desavenças nas relações familiares, busca do imaginário urbano, vontade de viver outras experiências (BAPTISTA, 1998, p.106).

Essa corrente migratória permitiu considerável desenvolvimento da economia capitalista da cidade, mobilizando parcela considerável desta população para as indústrias, resultando no surgimento de uma força de trabalho considerada pouco qualificada. Entretanto, a inserção dos nordestinos no mercado de trabalho contrariou a ideologia negativa construída anteriormente, pois estes se mostraram indivíduos trabalhadores, de aspirações modestas e dóceis (SINGER, 1998). O crescimento econômico, por sua vez, solicitou, cada vez mais, mão de obra de baixa qualificação, reservando a esses trabalhadores salários mais baixos (PAIVA, 2004; VILLA, 2017).

As migrações nordestinas seguiram crescentes durante as décadas de 50 e 60, período de acelerada industrialização e urbanização. Participaram da formação de uma "nova" classe operária nacional, que se tornou importante protagonista na sociedade urbano-industrial que emergia e divergia da "vanguarda operária" de origem europeia do início do século XX. A diferença era que enquanto a "vanguarda operária" aspirava à ascensão social, a "nova" classe operária nacional teria migrado para os centros industriais para fugir da miséria e das precárias condições de vida das áreas rurais do país e, ao chegarem ao lugar de destino, se sentiam gratificados com a sua nova condição de trabalho (SILVA, 2008).

O período entre 1979 e 1984 foi marcado pela mais prolongada e abrangente seca no Nordeste, atingindo todos os Estados e deixando um vasto rastro de miséria. Esse evento, mais uma vez, impulsionou a migração em massa dos nordestinos em direção a São Paulo (SILVA; PATRÍCIO; RIBEIRO; MEDEIROS, 2013), o que se repetiu entre 1990 e 1993 e, entre 1998 e 1999, quando a zona semiárida brasileira foi assolada mais uma vez por secas, acarretando um considerável volume de desemprego e a procura por melhores condições de vida em grandes centros urbanos (FUSCO, 2012).

Atualmente, a migração nordestina para a capital segue ocorrendo, contudo, em menor intensidade. Esse fluxo, ao longo dos anos, gerou como consequência uma drástica alteração da origem étnica da população que, por muito tempo, era acentuadamente de origem imigrante. A presença desse crescente número de indivíduos fomentou hostilidade e xenofobia, uma vez que o Brasil era marcado pelo regionalismo e os estereótipos eram explorados politicamente pelas elites locais que insistiam em acentuar as diferenças existentes entre São Paulo e os estados do Nordeste, desqualificando-os (PAIVA, 2004; VILLA, 2017). 


\section{O Bixiga como destino dos nordestinos}

Localizado no distrito da Bela Vista, o Bixiga é um dos mais antigos territórios da cidade de São Paulo e o seu povoamento remonta ao século XIX (SCARLATO, 1989). Várias discussões são travadas referentes a seu limite atual, contudo, não há consenso entre elas. Uma delas, por exemplo, levantada por Bitelli (2017), considera que sua delimitação é realizada pelas avenidas Nove de Julho e Brigadeiro Luis Antonio e pelas ruas Maria Paula e Cardeal Leme.

Além dos negros aquilombados preexistentes, recebeu italianos, principalmente do sul da Itália (LUCENA, 2013), que vislumbraram oportunidades de trabalho na cidade, onde podiam desempenhar funções diversas, principalmente como artesões, construindo ali oficinas, sapatarias, alfaiatarias e padarias (LUCENA, 1983). Com a chegada deles, trazendo consigo sua música, cultura, religião, culinária e arquitetura, nascia também o mito do Bixiga italiano, uma vez que esses imigrantes se tornaram o símbolo representativo da região, ofuscando, assim, a presença da comunidade negra que ali já residia (CASTRO, 2008).

Os italianos instalaram-se na porção mais baixa do território e construíram, no final do século XIX e começo do século XX, casarões com o intuito de abrigar várias famílias em uma mesma edificação, originando, assim, os famosos cortiços (LUCENA, 2013; PAIVA, 2004). A permanência dos ex-escravos após a abolição da escravatura nas antigas margens do rio Saracura, hoje canalizado e aterrado (CASTRO, 2008; NASCIMENTO, 2016), tornou-o também uma referência negra, território denominado como quadrilátero negro (CASTRO, 2008).

Mas foi a partir da década de 1950, como já dito anteriormente, que o Bixiga se tornou uma opção interessante de moradia para os migrantes nordestinos, por ser central e pela presença dos cortiços, espaços sublocados pelos italianos, que apresentavam baixo custo de aluguel. Ao passo que as antigas famílias italianas abandonavam o Bixiga por razões diversas, os nordestinos foram ocupando seu lugar e a população de ítalo-paulistas, que um dia foi dominante, passou a diminuir cada vez mais (SCARLATO, 1989).

Os cortiços, então, passaram a abrigar além dos nordestinos, os mineiros e outros migrantes nacionais, tornando o Bixiga um local multiétnico, um território de migração. Importante esclarecer que nos territórios de migração há uma constante disputa por inserção, pertencimento e visibilidade; são espaços complexos que se constroem sobrepondo-se e ocultando sujeitos e estão em constante transformação. Alguns indivíduos são vistos como os representantes do lugar e outros são considerados intrusos pela sociedade, tendo seus costumes, hábitos e culturas desprezados e, em muitos casos, se tornam um incômodo para a região (PAIVA, 2004; PAIVA, 2011; LUCENA, 2013).

Hoje o Bixiga se caracteriza pela sua rica diversidade, tendo se tornado um espaço para indivíduos de diversas etnias, sendo considerado um território principalmente afroitaliano-nordestino-mineiro, onde o contato com a alteridade é rotineiro e, assim, as relações de hospitalidade também são. É referência para múltiplas manifestações culturais, para vivenciar diferentes estilos de vida, de pensar, de agir e de trabalhar. Especialmente, é essa característica de multiplicidade de referências culturais das 
comunidades que torna este lugar peculiar (CASTRO, 2008).

A imagem que se propaga, por intermédio da mídia e dos seus frequentadores, é a do Bixiga sinônimo de lazer e da cultura. A segregação social, quando aparece, é mascarada e entendida como "manifestações folclóricas". Ideologicamente, reforça-se a italianidade do território, como se essa característica fosse tão forte quanto no período de sua formação (SCARLATO, 1989).

\section{Procedimentos Metodológicos}

Uma vez que esta pesquisa busca investigar aspectos relacionados ao comportamento humano, acreditou-se ser adequado para o seu desenvolvimento o enfoque qualitativo, uma vez que esta busca compreender, detalhadamente, características e significados situacionais apresentados pelos sujeitos (CRESWELL, 2010).

Dessa forma, foi adotada como estratégia metodológica a pesquisa exploratória, com a finalidade de obter os pontos de vista dos sujeitos, expressos abertamente, em uma situação de diálogo. Essa estratégia permite que o pesquisador tenha liberdade para desenvolver o tema proposto em qualquer direção que considere pertinente, podendo explorar mais amplamente a questão a ser investigada (CRESWELL, 2010).

Para tanto, foram realizadas diversas visitas ao Bixiga, com a finalidade de obter um panorama da região; nesse sentido, a pesquisa considerou ambientes que não são relacionados diretamente à temática nordestina, mas cujos proprietários, funcionários e frequentadores vivenciam contato direto com os migrantes nordestinos da região, bem como aqueles que acentuam representações da presença nordestina no território. Restaurantes cujos cardápios contemplam pratos típicos da culinária nordestina foram frequentados, mercearias que comercializam comida, ingredientes e produtos gerais vindos diretamente do Nordeste e que funcionam como "casas do Norte" foram visitadas, cafés e coquetéis foram degustados e objetos museológicos foram fruídos para, informalmente, observar sua dinâmica e conversar com pessoas acerca de suas vivências cotidianas, com o intuito de obter referências sobre temas que seriam interessantes de abordar durante as entrevistas.

Após as visitas aos estabelecimentos e pesquisas em páginas da internet, alguns se destacaram e se tornaram os objetos de estudo: 1) um restaurante que abraça a temática nordestina; 2) uma mercearia que também se coloca como "casa do Norte" e que comercializa comidas, ingredientes e produtos diversos trazidos diretamente do Nordeste; 3) uma cafeteria tradicional do bairro; 4) um bar; 5) um museu. Salienta-se, aqui, que os três últimos são classificados como ambientes não vinculados à temática nordestina.

Foram, então, utilizadas como técnicas de coleta a observação participante e entrevistas abertas semiestruturadas - gravadas e transcritas -, com a finalidade de registrar as experiências e percepções relacionadas à hospitalidade e as suas dimensões vividas pelos indivíduos, que aqui são representados por migrantes nordestinos e a sociedade de acolhimento no Bixiga (FLICK, 2009; GIL, 2016). Os dados coletados para serem analisados são provenientes das entrevistas realizadas com sete migrantes 
nordestinos e quatro paulistanos, tendo sido interrompido o recrutamento de novos entrevistados após o corpus ter atingido a saturação teórica, ou seja, os discursos referentes às questões abordadas começaram a se repetir (FLICK, 2009). Em sequência, os dados obtidos foram tratados analiticamente por meio da análise de conteúdo, em conformidade com o preconizado por Bardin (1977).

A análise de conteúdo pautou-se na categoria desenvolvida a priori, acolhimento e pertencimento - agrupados por serem complementares - referente às dimensões da hospitalidade, que surgiu por uma instância exterior, ou seja, advém do quadro teórico construído para a fundamentação da pesquisa. Já as categorias desenvolvidas a posteriori surgiram com base em procedimentos exploratórios, uma vez que o quadro de análise não estava completamente determinado. Essas categorias definidas emergiram do discurso, do teor das respostas dadas pelos entrevistados. Nesse sentido, sentiu-se a necessidade de agregar ao grupo de categorias os seguintes temas: hostilidade, xenofobia e Bixiga italiano.

Apesar da escolha dos respondentes ter sido aleatória, foi providencial a diversidade de perfis encontrados, pois distintos pontos de vista puderam ser evidenciados. Por sua vez, o roteiro das entrevistas contemplou temas como: migração nordestina para São Paulo, os nordestinos no Bixiga, hospitalidade, acolhimento, pertencimento, xenofobia, hostilidade, Bixiga italiano, dentre outros.

Transcritas na íntegra, houve a preservação das expressões idiomáticas, gírias e vícios de linguagem, com o intuito de obter dados legítimos. Foram preservadas também as identidades dos entrevistados, apresentadas por siglas, cujas falas estão diferenciadas no texto pelo recurso itálico e disponibilizadas no tópico seguinte deste trabalho.

\section{A hospitalidade e suas dimensões inseridas na dinâmica entre migrantes nordestinos e a sociedade de acolhimento no Bixiga}

\subsection{O paradoxo do Bixiga: acolhimento, pertencimento e hostilidade}

O processo de aceitação do migrante em uma nova sociedade não é um processo rápido nem fácil, uma vez que o hospedeiro não tem a intenção primária de integrar o hóspede à sociedade, transformando-o em um nativo (BOUDOU, 2017). Nesse sentido, acolher alguém representa um ato contraditório: ora é considerado o momento inaugural e decisivo da hospitalidade e "ora a contamina a ponto de dissolver e anular o ritual da hospitalidade por rituais de passagem numa lógica da integração que transforma o hóspede num membro integral da comunidade hospedeira." (MONTADON, 2011, p. 1171).

Esse paradoxo é importante de ser levado em consideração quando envolve um migrante, uma vez que, ao sair da sua terra, "[...] pode encontrar igualmente e ao mesmo tempo uma certa forma de isolamento e de solidão. [...] A apropriação de um lugar que não é seu é coisa nem evidente nem fácil" (MONTADON, 2011, p. 34-35). A relação entre migrantes e hospitalidade, sobretudo no tocante à questão do acolhimento e pertencimento é amplamente discutida na literatura (BOUDOU, 2017; MONTADON, 2011; GRASSI, 2011, DENCKER, 2013), em razão da inserção dos migrantes à sua nova 
realidade. Dessa forma, a categoria acolhimento e pertencimento buscou investigar o quão integrados ao Bixiga os migrantes nordestinos se sentem. Logo de início, o que se observou foi que esse sentimento de isolamento referido por Montadon (2011), contudo, não se mostrou presente, uma vez que os migrantes nordestinos entrevistados demonstraram terem sido bem acolhidos e, hoje em dia, se sentem pertencentes ao local, a exemplo dos relatos:

[...] eu me sinto bem parte do bairro mesmo, pra mim é como se eu já tivesse nascido aqui. A amizade que nós temos com o pessoal que é nascido e criado na Bela Vista faz a gente ficar bem acolhido (E.S.S., 42 anos, baiana, proprietária de bar, 2020).

Eu me sinto como se eu estivesse lá na minha cidade [...]. Sou bem conhecido aqui dentro do bairro, eu passo pelo bairro e todo mundo me cumprimenta, eu cumprimento todo mundo, da criança ao velho, então eu me sinto acolhido. Eu acho que eu sou meio italiano e meio nordestino (M.J., 44 anos, baiano, proprietário de pizzaria, 2020).

É possível relacionar essa característica de lugar acolhedor conferida ao Bixiga à sua origem. Por ser um território de migração e ter sido constituído por sujeitos que escapavam de situações difíceis, como ex-escravos, italianos que fugiam de situações de vulnerabilidade e nordestinos que buscavam melhores condições de vida, a empatia se tornou precursora da acolhida. As dificuldades encontradas na vida se tornaram o vínculo principal entre os sujeitos, como é possível observar no relato:

Todos que chegaram ao bairro estavam em situações similares, difíceis. Os negros estavam fugindo do cativeiro, os italianos estavam fugindo da fome, os nordestinos também, todos estavam saindo de baixo, então meio que tem esse elo de ligação, porque estava todo mundo na pior. Aqui nunca foi um bairro de pessoas bem sucedidas, se você analisar o bairro vai perceber que aqui era uma terra que ninguém queria (P.S., 72 anos, maranhense, sócio-fundador de museu, 2020).

Outro aspecto levantado pelos respondentes, que predispôs o acolhimento dos migrantes nordestinos recém-chegados no Bixiga, foi a presença de uma comunidade nordestina já ali estabelecida, fazendo com que os novos migrantes se sentissem bem recebidos, mais confortáveis, formando uma rede de apoio, de cooperação:

[...] no geral, é um bom lugar pra tipo se uma pessoa vier do nordeste sozinho e aí ela chega aqui e vê um monte de nordestino, conhece uma pessoa que seja da cidade dela... eu acho que isso é bom, a pessoa se sente mais acolhida. Se sente mais em casa, tal... porque é muito ruim morar longe da família, mudar de uma cidade assim sem conhecer ninguém. Então, nesse sentido acho que ele é acolhedor (A.S.O., 31 anos, paulistana, profissional de rádio e TV, 2019).

[...] então eu percebo que é um bairro que tem muito migrante e é um lugar que você se sente em casa, acolhido. Você sabe que pode falar com fulano, contar com ciclano [sic] e tudo mais. É um bairro que 
recebe muito bem, com um traço cultural muito forte e muito presente. $\mathrm{Eu}$ percebo muito a cultura nordestina, mas eu não sei dizer direito porque faz tempo que eu não venho pra cá. Mas eu percebo um povo muito acolhedor, principalmente na parte do Nordeste, que é o que eu mais tenho contato por aqui. Eu me sinto acolhida aqui. Se tivesse só eu sozinha aqui... eu me sentiria em casa, me sinto pertencente (K.F.A., 23 anos, paulistana, enfermeira, 2019).

A opinião dos entrevistados compactua com o expresso por Dencker (2013) e Vandervoordt (2017), ao referir que os migrantes tendem a formar comunidades que têm comportamentos similares, costumes e traços culturais em comum, o que estimula a integração e propicia a origem do sentimento de pertencimento. Por existir a possibilidade da sensação latente de exclusão e de isolamento em alguns migrantes, estes tendem a se aproximar de pessoas com situações semelhantes, a fim de se sentirem mais seguros, confortáveis (MCLAREN, 2003).

Grassi (2011, p. 53) agrega ao pensamento ao discorrer acerca da questão daquele que, em busca de acolhimento, ultrapassa os espaços e enfatiza que os “[...] indesejáveis são repelidos para as fronteiras, só se convidam os amigos, semelhantes"; dessa forma, ilustra o motivo pelo qual é frequente que migrantes afins se agrupem, como forma de fortalecimento, de se sentirem acolhidos ou pertencentes. Isso é importante, pois "[...] o pertencimento é vital", conforme refere Grinover (2006, p. 35).

Nesse sentido, a condição de mobilidade representa uma permanente recomposição e ressignificação das redes de relações sociais (VILLA, 2017; HALL, 1996). A hospitalidade, o acolhimento e o pertencimento, assim, são experiências de alteridade (MONTADON, 2011), pois o relacionamento entre indivíduos de diferentes origens e personalidades faz com que os comportamentos sejam manifestados de forma particular, acarretando um sentimento de união entre as pessoas que se identificam e demarcando a presença dos que são considerados diferentes (DENCKER, 2013).

Tendo em mente o exposto, é essencial entender que o ato de "receber o outro" está vinculado à questão da territorialidade - responsável pela formação dos grupos sociais e pelo sentimento de pertencimento, ao passo que os sujeitos desenvolvem seus próprios códigos mediante as relações ali estabelecidas. Para que os sujeitos que pertencem a grupos diferentes sejam recebidos de maneira inclusiva, cabe à sociedade que os acolhe conciliar a multiplicidade de códigos e referências para que a comunicação seja bem sucedida, tendo consciência de que, mesmo assim, a convivência não será isenta de conflitos (DENCKER, 2013).

Para Derrida (2003), o ato de acolher requer o reconhecimento da singularidade dos indivíduos e a ausência de imposições de normas e culturas entre o hospedeiro e o hóspede, sendo o acolhimento, na verdade, uma situação rica de troca. Contudo, como já mencionado anteriormente, o caráter incondicional preconizado por Derrida (2003) é, por muitos, considerado perigoso, por desconhecimento das intenções dos envolvidos no processo de acolhimento e, assim, a hospitalidade preconiza a dualidade de oferecer enquanto mantém uma distância segura entre os indivíduos. Portanto, como é esperado, nessas dinâmicas sociais nem tudo é utópico e, frequentemente, o migrante nordestino, 
na sua posição de "estrangeiro", pode também ser encarado como um inimigo (BOUDOU, 2017). No contexto da pesquisa, a hostilidade tornou-se uma categoria, pois ela emergiu do discurso de alguns entrevistados. Exemplos da presença de hostilidade por parte da sociedade de acolhimento foram relatados, como pode se observar no depoimento de M.J. (44 anos, baiano, proprietário de pizzaria, 2020).

Foi assim que eu comprei uma briga grande com os italianos, porque, além da pizza, eu agreguei outras coisas da culinária italiana, e aí eu comprei uma briga grande com os Basilicata que são os mais antigos aqui do bairro; eles acham que eles mandam e que todo mundo tem que obedecer. Fugi essa regra, não quis obedecê-los. O nome da minha pizzaria é Pizzaria e Cantina 13 de Maio, eles têm uma padaria a qual o nome fantasia é 13 de Maio. E eles, por sua vez, acham que eu não posso usar o nome 13 de maio. Essa briga já tá aí há mais de três anos e ela ainda vai longe. Eles entram com liminar, eu entro com outra, tento patentear de uma forma e não dá, inclusive entrei com uma patente faz uns dois anos, foi indeferida, entrei com um recurso, com advogado etc. e tal [sic]. Eu já falei para eles que a gente vai brigar até o final. Primeiro porque eu não vou mudar o nome, ponto. Segundo, porque eu não me curvo perante a eles. Eles não chegaram onde estão pelos seus próprios méritos, eles são a terceira geração dos Basilicata. Então, eu comprei essa briga e vou até o final, eu não tenho medo desse tipo de gente que acham [sic] que são os donos daqui que, porque eles têm dinheiro, todo mundo tem que se curvar e bater continência.

A hostilidade referida no trecho anterior é destacada por Perazzolo, Santos e Pereira (2013), ao expressarem que quando o migrante não é percebido ou a sua individualidade não é respeitada no processo do acolhimento, o que ocorre na verdade é a imposição sobre ele de poder, das normas e dos ditames daquele que deveria acolher, configurando uma experiência narcisista. A linha entre a hospitalidade e a hostilidade, nesse aspecto, é tênue. À medida que aquele que recebe não acolhe o hóspede, surgirá agressão, hostilidade ou indiferença, fazendo com que, com considerável frequência, o migrante se sinta excluído naquele "novo" lugar, não se sentindo acolhido ou pertencente àquela nova realidade (MONTADON, 2011). Dessa forma, é interessante observar que, embora os migrantes se sintam acolhidos e pertencentes ao Bixiga, o acolhimento conferido pela sociedade que os recebeu não é incondicional, uma vez que foi evidenciado que imposições de normas e condutas são realizadas para que a convivência entre as partes possa a ser pacífica.

\subsection{O Bixiga italiano e a xenofobia}

Um aspecto que despertou a atenção durante a pesquisa de campo foi a evidência da falta de representatividade dos migrantes nordestinos no Bixiga, apesar de, visivelmente, eles constituírem a porção majoritária da população que mora e trabalha nesse lugar. $\mathrm{O}$ aspecto levantou o questionamento sobre qual seria o motivo do território ainda ser considerado reduto dos italianos, quando eles sequer continuam ali, tendo restado apenas seus descendentes. A investigação das razões para o apagamento da comunidade nordestina no Bixiga é, contudo, dificultada pela escassez da literatura acerca 
dessa temática.

Uma vez que a presença nordestina no Bixiga não é contemplada pela literatura, empiricamente, por meio das entrevistas, isso foi investigado e, em decorrência, houve a criação da categoria Bixiga italiano. Ao serem questionados se o Bixiga ainda é um território italiano, houve unanimidade no teor da resposta, sendo representada pelas falas a seguir dos entrevistados:

O bairro do Bixiga, apesar dessa imagem equivocada de bairro italiano, que há muito tempo deixou de ser, abriga gente das mais diversas localidades. Mas pode-se dizer que, hoje em dia, predominantemente, é um bairro nordestino, negro e italiano (S.B., 72 anos, paulistano, proprietário de cafeteria, 2020).

[...] hoje, ele não é nem mais um bairro italiano, ele é mais um bairro nordestino do que italiano. Inclusive, o dinheiro que corre por aqui é todo fruto do trabalho dos nordestinos (M.J., 44 anos, baiano, proprietário de pizzaria, 2020).

O Bixiga italiano foi apenas um momento. Poucos sabem, mas inicialmente o bairro era um quilombo, o Saracura. Então, originalmente, o Bixiga é um bairro negro. Até o nome Bixiga é um equívoco. Usam esse nome principalmente com a escrita contendo o "i" porque faz alusão ao modo como os italianos falavam a palavra Bexiga, por causa do sotaque. Mas não era pra ser assim, nem todo mundo fala dessa maneira e só porque os italianos que um dia foram influentes aqui falavam assim, não quer dizer que necessite ser o nome do bairro. Na verdade, aqui é a Bela Vista. Os negros que, originalmente, eram os habitantes do bairro, foram silenciados. Vejo isso acontecendo com os nordestinos também (S.B., 72 anos, paulistano, proprietário de cafeteria, 2020).

Acho que não... o bairro hoje é nordestino. A maioria dos moradores aqui são nordestinos, italianos não tem mais. Tem aqui descendentes de italianos, não existe essa presença forte italiana mais. É considerado um bairro italiano, o pano de fundo é italiano. Mas falta considerar o Bixiga como bairro nordestino (P.S., 72 anos, maranhense, sócio-fundador de museu, 2020).

O cenário italiano é o pano de fundo. Se você for na Basilicata, se você for numa dessas cantinas italianas aqui do Bixiga, você vai na cozinha... os trabalhadores são todos nordestinos. Italiano não tem nenhum. Tem filho e neto de italiano, mas os trabalhadores braçais, que fazem as coisas lá, são todos do Nordeste - mas estão fazendo uma comida italiana. Você não pode pegar um pão da Basilicata e dizer que é um pão de Pernambuco. As pizzas, por exemplo, também é feita [sic] por nordestinos (P.S., 72 anos, maranhense, sócio-fundador de museu, 2020).

[...] na 13 de Maio, que é considerada a principal artéria do Bixiga, a economia hoje tá na mão dos nordestinos. Se você pegar do zero ao mil, ou seja, de ponta a ponta até a Brigadeiro, toda a culinária é feita pelo pessoal do Nordeste e muitos deles são também os proprietários dos 
estabelecimentos. Da escadaria para lá também tem vários barzinhos de nordestinos e, inclusive, tem uma coisa curiosa: tem um restaurante japonês nessa rua que é de um pernambucano, ou baiano, agora não sei, mas sei que é nordestino. Certa vez, entrei lá e vi que não tinha japonês nenhum, só tinha nordestino, mas o dono de lá trabalhou muitos anos em restaurante japonês e acabou montando esse negócio para ele (P.S., 72 anos, maranhense, sócio fundador de museu, 2020).

O consenso entre todos os entrevistados sobre a predominância de nordestinos em detrimento dos italianos foi evidenciado; a consciência da falta de representatividade dos migrantes nordestinos também é consenso, como é possível observar nos depoimentos que seguem:

Os italianos no Bixiga têm uma representatividade. A exemplo da igreja da Achiropita, ela representa os italianos. Os negros têm uma representatividade na Vai-Vai, aquela região era um quilombo. Já os nordestinos não têm representatividade e isso é uma dívida que o Bixiga tem com essa comunidade, falta algo que a represente, mas aqui é essa mistura (P.S., 72 anos, maranhense, sócio-fundador de museu, 2020).

Mas sobre a falta de representação dos nordestinos, acredito que seja pelo pouco tempo... da década de 1950 para cá, e é uma mistura muito grande, né? As pessoas pensam que Nordeste é uma coisa só, mas são povos muito diferentes e até ter esse ajuste e criar um enraizamento no bairro demora um pouco (P.S., 72 anos, maranhense, sócio-fundador de museu, 2020).

Indagados sobre as razões do apagamento dos nordestinos em contraste com o destaque da cultura italiana, os entrevistados apresentaram pontos de vista distintos. Uns enfatizaram que os italianos têm maior capacidade de divulgação, se relacionam com a imprensa, recebem patrocínio para os seus eventos e, por isso, têm mais visibilidade. Contudo, parte dos entrevistados tinha uma percepção em comum: a xenofobia em relação aos nordestinos. Essas duas visões podem ser observadas nas narrativas a seguir:

[...] os italianos têm mais poder de divulgação, são mais espalhafatosos, têm a festa da Achiropita que é a festa italiana mais tradicional de São Paulo, então faz com que... por exemplo, quando começa a festa da Achiropita, um dos patrocinadores da festa é a TV Globo, então começa a divulgar todo dia e aí vira um bairro italiano. Não acho que tenha a ver com a valorização do estrangeiro em detrimento do brasileiro, até porque quando os italianos chegaram aqui não estavam em situações favoráveis de vida. Mas é que tem muita presença... divulga-se muito (P.S., 72 anos, maranhense, sóciofundador de museu, 2020).

Eu acho que é essa síndrome que a gente tem de que tudo que vem de fora é melhor. Então, falar que é um bairro italiano soa melhor do que falar que é um bairro de nordestino, apesar de eu achar que aqui é um bairro mais nordestino que italiano. Eu diria que os donos dos restaurantes são italianos, até das cantinas lá da 13 de maio, mas os funcionários são todos nordestinos, todos... todos... e todos moram por 
aqui, é um ou outro que mora longe, mas a maioria mora por aqui. Então, acho que muito desse negócio, tipo, realmente foi um bairro italiano, as cantinas mais antigas de São Paulo, um negócio assim, mas, hoje em dia, acho que não tem nem como comparar a presença dos nordestinos daqui com a presença dos italianos. Mas rola um certo preconceito. A gente tem bastante preconceito com a presença nordestina, eu acho, apesar de eu não sofrer com esse preconceito, eu sei que ele existe. E eu acho que tem uma questão nisso também, das pessoas acharem melhor ser um bairro italiano do que um bairro nordestino (A.S.O., 31 anos, paulistana, profissional de rádio e TV, 2019).

No Brasil existe ainda uma mentalidade muito colonial. Apesar de achar que isso vem mudando devido ao acesso mais fácil às informações, acho que um dia viveremos um momento bom nesse sentido, mas hoje ainda há muito preconceito. Mas, grosso modo, devido a essa mentalidade colonial, valoriza-se a presença dos estrangeiros e suprimem a expressão dos nacionais. Isso também aconteceu no bairro da Liberdade. A gente pôde ver a mobilização negra, com toda razão, quando houve a mudança do nome da estação para Japão-Liberdade. Por que mudar, sabe? Qual a necessidade? Não existe só japonês lá, do mesmo modo que não existe só italiano aqui. Na verdade, nenhum lugar do Brasil é apenas composto por uma única etnia, é sempre uma experiência multicultural. Você sabia que aqui tem um restaurante vietnamita? Tem japonês também... ou seja, tem gente de toda parte. Mas ficam apagados por causa desse mito do bairro ser italiano. Isso é um mito (S.B., 72 anos, paulistano, proprietário de cafeteria, 2020).

Pra mim, não existe esse negócio de paulista, nordestino. Pra mim, na sociedade, todo mundo é igual. Esse negócio de distinguir por conta de origem, de sexo, de cor eu acho que é uma ignorância. Mas infelizmente não só aqui em São Paulo, mas em todo lugar ainda fazem essas distinções. São os verdadeiros coronéis, que acham que, pelo fato de terem dinheiro, de terem um patrimônio, são os donos da verdade, os donos da realidade e que todo mundo tem que se curvar perante eles (M.J., 44 anos, baiano, proprietário de restaurante, 2020).

Os relatos condizem com o expresso por Estrela (2003) ao referir que os migrantes nordestinos em São Paulo enfrentam problemas de xenofobia desde as primeiras décadas do século XX. Enfatiza-se, aqui, que a xenofobia significa uma manifestação ancorada em preconceitos que são refutados pela racionalidade e pela ciência, sendo representada por visões negativas estereotipadas contra indivíduos de diferentes etnias (RZEPNIKOWSKA, 2019; KUBOTA, 2017; MCLAREN, 2003).

No pensamento comum, soa ilógico utilizar o termo "xenofobia" para caracterizar o preconceito contra os nordestinos, quando se fala de indivíduos de um mesmo país. Entretanto, considerando os relatos referentes a essa categoria de análise, é possível relacioná-los ao discurso colonial, que consiste em apresentar o colonizado como um degenerado baseando-se apenas na origem étnica, com o intuito de justificar a exploração e estabelecer dominação sobre ele (MOURÃO; ABRANTES, 2019). Os indivíduos são, dessa forma, inferiorizados, objetificados e enxergados pelas lentes do estereótipo 
(BHABHA, 2019; MACGILCHRIST; AHLRICHS; MIELKE; RICHTERA, 2017; MOURÃO; ABRANTES, 2019).

Pôde-se observar, por meio dos relatos, que a xenofobia pode ser manifestada de diversas maneiras, sobretudo na linguagem, por vezes travestida de brincadeira, o que torna a hostilidade experienciada por alguns nordestinos imperceptível (ESTRELA, 2003). Muitas vezes é reproduzida nas falas dos próprios migrantes nordestinos, que, de tanto ouvirem, acabaram interiorizando essa mentalidade, taxando-a de senso comum, conforme se observa nos seguintes relatos obtidos quando os entrevistados foram questionados sobre a existência de xenofobia contra os nordestinos:

Não... mas também não sei se é porque a minha aparência não é muito aparência de nordestino. Antigamente, o pessoal chamava a pessoa de Paraíba, essas coisas, entendeu? Mas hoje em dia, não (R.N.O., 67 anos, cearense, proprietário de restaurante, 2019).

Não tenha dúvida, não só eu, mas todo nordestino sofre preconceito. Hoje... hoje não mais tanto. Mas, antigamente, tudo que dava errado em São Paulo era: "olha a baianada... olha o baiano... olha o caipira". Hoje não mais, essa coisa meio que ficou sem graça, mas antigamente, nossa, se você trabalhasse num lugar em que tivesse cem empregados e só você fosse nordestino, você era só baianada (M.J., 44 anos, baiano, proprietário de restaurante, 2020).

[...] às vezes, sai mais da minha boca, né? Quando eu digo: "quem diria... uma baianinha, que não tinha família aqui, vim sozinha, desde cedo sofri bastante...", eu mesma tiro brincadeira comigo mesma, entendeu? Mas o pessoal, não (E.S.S., 42 anos, baiana, proprietária de bar, 2020).

Além disso, considerados subalternos, inferiorizados e omitidos, muitos nordestinos são submetidos a uma rotina de trabalho compulsória e a preços abusivos de moradia, inclusive nos cortiços (PAIVA, 2004; TEDESCO, 2017), como é possível observar no expresso pelos depoentes:

Os moradores são explorados, não têm fiador. Mesmo que tenham dinheiro para alugar um apartamento, não têm como alugar... não têm fiador, vai pedir um seguro fiança lá na Porto Seguro e não dão, então aceita a exploração, mesmo tendo dinheiro (P.S., 72 anos, maranhense, sócio-fundador de museu, 2020).

[...] muitos moram nas habitações compartilhadas, que um dia foram chamadas de cortiço. São casas que possuem um dono, um locatário que subloca os cômodos da casa para pessoas avulsas, não necessariamente famílias, como um dia costumou ser. Nesses lugares, até 5 pessoas podem morar em um mesmo quarto, tem beliches e é assim que funciona. Nessas habitações têm muitos nordestinos; eles escolhem morar pelo bairro porque trabalham nas redondezas e morar mais distante seria um problema em virtude do deslocamento até o trabalho, necessitando gastar com transporte, seria mais oneroso para eles (S.B., 72 anos, paulistano, proprietário de cafeteria, 2020). 
Dessa forma, é possível inferir que a ideologia construída há anos sobre o Nordeste, como uma região pobre e atrasada, infelizmente, refletiu-se - e segue sendo refletida - nos migrantes nordestinos. Eles são vistos como flagelados, enquanto a influência italiana é exaltada, uma vez que a grandeza do bairro foi associada ao trabalho desses imigrantes. Apesar de ser composto predominantemente por migrantes nordestinos, o mito do Bixiga italiano é mantido e, de maneira velada, os nordestinos são encarados por muitos como invasores que ocasionaram a perda da identidade cultural italiana do lugar.

\section{Considerações finais}

A escolha do Bixiga como locus da pesquisa deu-se pelo fato de ser considerado um local multiétnico, onde negros, nordestinos, italianos e outros brasileiros compartilham o cotidiano. Essa comunidade plural torna o espaço rico e peculiar, o que potencializa os estudos para investigação das complexas dinâmicas sociais e relações de hospitalidade que ali são estabelecidas. Reconhecido até os dias atuais como um território italiano, paradoxalmente, no Bixiga, os italianos atualmente são representados apenas por seus descendentes.

Nesse contexto, os migrantes nordestinos entrevistados, que escolheram o Bixiga como "novo lar", expressaram se sentirem acolhidos e pertencentes a ele. Por possuir pequenas dimensões territoriais, as pessoas se conhecem, convivem de perto, compartilham suas histórias, sendo a vivência ali relativamente tranquila.

Ainda no tocante ao acolhimento, a criação de vínculos entre os nordestinos recém-chegados ao Bixiga com outros nordestinos já estabelecidos mostrou-se importante para a evocação de um senso de pertencimento na sociedade de acolhimento. Em contrapartida, observou-se que o acolhimento dos nordestinos ali não é incondicional, uma vez que conflitos foram expostos pelos entrevistados, originados em virtude da imposição de regras de conduta e de condições por parte de indivíduos considerados tradicionais no território, evidenciando, assim, a existência de momentos de hostilidade entre migrantes nordestinos e a sociedade de acolhimento.

Além disso, a falta de representatividade dos migrantes nordestinos no Bixiga foi um pertinente achado da pesquisa. Apesar das claras contribuições deles para o seu desenvolvimento, é perceptível o apagamento dessa comunidade no território. Foi evidenciado que o principal motivo para essa invisibilidade é a xenofobia contra esses migrantes, fazendo com que os nordestinos sejam encarados como indivíduos inferiorizados, indignos de reconhecimento, enquanto os imigrantes italianos - hoje representados por seus descendentes - em compensação, são vistos como os responsáveis por tornar o Bixiga referência nacional.

Por fim, é importante ressaltar que a escassez de literatura acerca da temática configurou um grande desafio para o desenvolvimento deste trabalho. Faz-se necessário, desse modo, que estudos contemporâneos sobre a migração nordestina para a cidade de São Paulo sejam realizados. O tema é pertinente por acreditar que estudos que 
demonstram a dinâmica da mobilidade humana, apontando sua complexidade, e que mostram suas motivações, causam impactos positivos e contribuem para o combate à xenofobia, contribuindo cada vez mais para que a integração dos migrantes à sua nova realidade seja efetivada.

\section{Referências bibliográficas}

BAPTISTA, Dulce Maria Tourinho. Nas Terras do Deus-Dará: nordestinos e suas redes sociais em São Paulo. 1998. Tese (Doutorado em Ciências Sociais) - Pontifícia Universidade Católica de São Paulo, São Paulo.

BARDIN, Laurence. Análise de conteúdo. Lisboa: Edições 70, 1977.

BHABHA, Homi K. O local da cultura. Belo Horizonte: UFMG, 2019. p. 121-141.

BENVENISTE, Émile. O vocabulário das instituições indo-europeias. Campinas: Unicamp, 1995.

BITELLI, Fábio Molinari. Dimensões da hospitalidade no espaço público: Manifestações culturais no bairro do Bixiga em São Paulo. 2017. Dissertação (Mestrado em Hospitalidade) - Universidade Anhembi Morumbi, São Paulo.

BOFF, Leonardo. Virtudes para um outro mundo possível: hospitalidade, direito e dever de todos. Petrópolis: Vozes, 2005.

BOUDOU, Benjamin. Elementos para uma antropologia política da hospitalidade. In: BRUSADIN, Leandro Benedini (Org.). Hospitalidade e dádiva: a alma dos lugares e a cultura do acolhimento. Curitiba: Prismas, 2017. p. 99-118.

CAMARGO, Luiz Octávio de Lima. Os interstícios da hospitalidade. Revista Hospitalidade, v. 12, $\mathrm{n}^{\circ}$. especial, 2015.

CASTRO, Márcio Sampaio de. Bexiga: um bairro afro-italiano. São Paulo: Annablume, 2008. p. 37-69.

CHUEIRI, Vera Karam; CÂMARA, Heloísa Fernandes. Direitos humanos em movimento: migração, refúgio, saudade e hospitalidade. Direito, Estado e Sociedade, no . 36, p. 159-162, 2014.

CRESWELL, John W. Projeto de pesquisa: métodos qualitativo, quantitativo e misto. Porto Alegre: Artmed, 2010. p. 26-206

DENCKER, Ada de Freitas Maneti. Hospitalidade e interação no mundo globalizado. Revista Rosa dos Ventos, v. 5, n. 1, p. 1-11, 2013.

DERRIDA, Jacques. Cosmopolitas de todos os países, mais um esforço! trad. F. Bernardo, Coimbra: Minerva Coimbra, p. 44, [1997] 2001.

DERRIDA, Jacques. Anne Dufourmantelle convida Jacques Derrida a falar de hospitalidade. São Paulo: Escuta, 2003.

ESTRELA, Ely Souza. Os sampauleiros: cotidiano e representações. São Paulo: Humanitas, 2003. p. 180-242.

FLICK, Uwe. Introdução à Pesquisa Qualitativa. Porto Alegre: Artmed, 2009. p. 143215. 
FUSCO, Wilson. Regiões Metropolitanas do Nordeste: origens, destinos e retornos de Migrantes. Revista Interdisciplinar de Mobilidade Humana, n. 39, p. 102, 2012.

GIL, Antônio Carlos. Como elaborar projetos de pesquisa. São Paulo: GEN/Atlas, 2016.

GRASSI, Marie-Clarie. Transpor a soleira. In: MONTANDON, A. O Livro da Hospitalidade: acolhida do estrangeiro na história e nas culturas. São Paulo: Senac, 2011. p. 45-53.

GRINOVER, Lucio. A hospitalidade urbana: acessibilidade, legibilidade e identidade. Revista Hospitalidade, ano III, n. 2, p. 29-50, 2006.

HALL, Stuart. Who Needs 'Identity'? In: HALL, S.; DU GAY, P. Questions of Cultural Identity. Londres/Thousand Oaks/Nova Deli: Sage, 1996, p. 1-17.

KANT, Immanuel. À paz perpétua. São Paulo: L\&PM, p. 50, [1795] 1989.

KUBOTA, Ryuko. Neoliberal paradoxes of language learning: xenophobia and international communication. Journal of Multilingual and Multicultural Development, v. 36, n. 5, p. 468-469, 2017.

LUCENA, Célia Toledo. Bixiga, amore mio! São Paulo: Pannartz, 1983. p. 62-94.

LUCENA, Célia Toledo. Bixiga revisitado. São Paulo: IBRASA, 2013. p. 26-227.

MACGILCHRIST, Felicitas; AHLRICHS, Johanna; MIELKE, Patrick; RICHTERA, Roman. Memory practices and colonial discourse: on text trajectories and lines of flight. Critical Discourse Studies, v. 14, n. 4, 342-343, 2017.

MCLAREN, Lauren M. Anti-immigrant prejudice in Europe: contact, threat perception, and preferences for the exclusion of migrants. Social Forces, v. 81, n. 3, p. 912-930, 2003.

MONTANDON, Alain. O Livro da Hospitalidade: acolhida do estrangeiro na história e nas culturas. São Paulo: Senac, p. 34-1171, 2011.

MOURÃO, Daniele Ellery; ABRANTES, Carla Susana Alem. Estudantes Africanos dos PALOP em Redenção, Ceará, Brasil: Representações, Identidades e Poder. Mediações Revista de Ciências Sociais, v. 25, n. 1, p. 67-69, 2020.

OJIMA, Ricardo; COSTA, José Vilton; CALIXTA, Renata Kissya. "Minha vida é andar por esse país..." A emigração recente no semiárido setentrional, políticas sociais e meio ambiente. Revista Interdisciplinar de Mobilidade Humana, n. 43, p. 149-167, 2014.

OLIVEIRA, Kleber Fernandes; JANNUZZI, Paulo de Martino. Motivos para migração no Brasil e retorno ao Nordeste: padrões etários, por sexo e origem/destino. São Paulo em Perspectiva, v. 19, n. 4, p. 134-143, 2005.

PAIVA, Odair da Cruz. Caminhos Cruzados: Migração e construção do Brasil moderno (1930-1950). Bauru: EDUSC, p. 21-270, 2004.

PAIVA, Odair da Cruz. Território de migração na cidade de São Paulo: entre a afirmação e a negação da condição do migrante. Idéias, n. 2, p. 13 - 30, 2011.

PERAZZOLO, Olga Araújo; SANTOS, Márcia Maria Cappellano; PEREIRA, Siloe. O acolhimento - ou hospitalidade turística - como interface possível entre o universal e o local no contexto da mundialização. Revista de Turismo y Patrimônio Cultural, v. 11, n.1, p. 45-55, 2013. 
PEREIRA, Gustavo de Lima. Democracia em desconstrução: da tolerância à hospitalidade no pensamento de Jacques Derrida / Gustavo de Lima Pereira. $1^{\mathrm{a}}$ ed. Florianópolis: Empório do Direito, 2017. p. 144-153.

RAFFESTIN, Claude. Réinventer l'hospitalité. Communications, n. 65, p. 166, 1997.

RZEPNIKIWSKA, Alina. Racism and xenophobia experienced by Polish migrants in the UK before and after Brexit vote. Journal of Ethnic and Migration Studies, v. 45, n. 1, p. 63-65, 2019.

SANTOS, Márcia Maria Cappellano; PERAZZOLO, Olga Araújo. Hospitalidade numa perspectiva coletiva: o corpo coletivo acolhedor. Revista Brasileira de Pesquisa em Turismo, v. 6, n. 1, p. 5-6, 2012.

SCARLATO, Francisco Capuano. Bixiga: uma ideologia geografica. Boletim Paulista de Geografia, p. 27-36, 1989.

SILVA, Uvanderson Vitor da. Velhos Caminhos, Novos Destinos: Migrante nordestino na Região Metropolitana de São Paulo. 2008. Dissertação (Mestrado em Sociologia) Faculdade de Filosofia, Letras e Ciências Humanas, Universidade de São Paulo, São Paulo.

SILVA, Virgínia Mirtes de Alcântara; PATRÍCIO, Maria da Conceição Marcelino; RIBEIRO, Victor Herbert de A.; MEDEIROS, Raimundo Mainar de. O desastre seca no Nordeste brasileiro. POLÊM!CA, v. 12, n. 2, p. 284-291, 2013.

SINGER, Paul. Economia Política da Urbanização. São Paulo: Contexto, 1998. p. 29126.

STEFANELli, Mércia Maria Cruz; BASTOS, Sênia. Missão Paz: Lugar de Hospitalidade e Acolhimento aos I-Migrantes na Cidade de São Paulo, SP. Revista Rosa dos Ventos, v. 8, n. 3, p. 258-259, 2016.

TEDESCO, João Carlos. Ser imigrante e empreendedor: lógicas e sentidos. Aspectos da imigração brasileira na Itália. Mediações - Revista de Ciências Sociais, v. 22, n. 1, p. 221224, 2017.

VANDEVOORDT, Robin. The politics of food and hospitality: how Syrian refugees in Belgium create a home in hostile environments. Journal of Refugee Studies. Oxford: Oxford University Press, p. 11-34, 2017.

VILLA, Marco Antônio. Quando eu vim-me embora. São Paulo: Leya, p. 11-34, 2017. 